\title{
A systematic outline for the osseous industries in the north pontic palaeometallic age
}

\begin{abstract}
The paper surveys current trends in systematizing bone and antler industries dated back to the 5th-1st millennia BC in the North Pontic area. The principles in question, however, seem to be adaptable to any of the many bone and antler contents of the Earth's archaeosphere. The reader is introduced to the classificatory concept of the author's own work which has never been explicated in full elsewhere. Usually, the North Pontic archaeologists definitely wish their archaeological record to be imposed into given classification completely. Yet the latter normally contains impermeable inherent limits set up by the analysts themselves, who basically face a scarcity of comprehensive expert data. Here, a solution to the problem is put forward based on systemic classificatory approach. This one refers to the osseous raw material structures and the ways these latter were bound to transform during manufacture. The author's techno classes concept of adapting, modifying and converting bone and antler during utilization goes back, in particular, to A.P. Borodovskiy's technological systematics. The traceology, in its turn, tends to embed almost anything identifiable into a system, since various means of functional analysis would be a bit of a help as verifying methods. At the same time, the artifact's technical function and the manner it was used are the issues of special research concern. Further, the ways in which past equipments (instruments, implements and accessories) might have affected other objects and substances or interacted with them, resulted in rational shapes and usewear patterns in artifacts of bone and antler. On that basis, tools, devices, joints, furniture and paraphernalia entities seem to be quite perceptive to the variability of the North Pontic worked osseous record. This kind of arrangement of the material, would it be derived from a site or an archaeological culture, may have been flexibly changed in terms of its units, whereas its principal sections are here to stay with no need them to be rearranged.
\end{abstract}

Keywords: north pontic area, the chalcolithic, the bronze age, the iron age, bone and antler industry, classification, traceology
Volume I Issue 4 - 2017

\author{
Valentine Pankowski \\ Department of Chalcolithic and the Bronze Age Archaeology, \\ The National Academy of Sciences of Ukraine, Ukraine
}

Correspondence: Valentine Pankowski, Department of Chalcolithic and the Bronze Age Archaeology, The National Academy of Sciences of Ukraine, Ukraine, Tel (044) 418-9195, Fax (044) 4I8-3306, Email vpns@ukr.net

Received: June 01, 2017 | Published: August 07, 2017
Abbreviations: TC, Technoclasses; NA, Natural Accomodats; PA, Partial Accomodats; NM, Natural Modificats; PM, Partial Modificats; C, Convertats

\section{Introduction}

The archaeological traceology provides effective facilities in identifying both artificial and natural modifications in bone, antler, and variety of faunal hard tissues from the North Pontic Palaeometallic Age. ${ }^{1}$ At that, the man-made items together with certain humanly modified objects come to form a special archaeological culture fraction called bone and antler industry. Here, the industry seems to pose "a system of interrelated artefact types made of the same material or substance". ${ }^{2}$ Having rallied artefacts into such raw material entity one may see them damaged and incomplete while the bygone functions and relations of these may seem highly obscure. On the other hand, it is well known how bizarre the shape and the trace mantle in osseous artefact can be, with its contiguity of both natural and anthropogenic marks. We are also aware of osseous naturfacts with barely noticeable man-induced alterations, as well as objects completely modified by forces of the nature, as those records which may shed light on past formation processes and cultural activities. ${ }^{1,3,4}$ Consequently, the separation of artefacts and industries is only a part of the systematization aimed to derive knowledge of the past. Hence, the review focuses upon developing comprehensive set of classifications for complexity of functional attributes, raw material structures and technological properties in artefactual bone and antler finds. Although AM Choyke's ${ }^{5}$ concept of the bone tool manufacturing continuum would have had an impact to the North Pontic systematics, it will be discussed elsewhere whenever and wherever it is possible. In the BTMC just mentioned, the chaîne opératoire relations, artefacts' use-life histories, imitation processes, and various social meanings all seem to stand out for some different goals and procedures in archaeological grouping. ${ }^{6}$

\section{Systematization goals, program and method}

The archaeologists usually obtain from artefact expertise and observations a number of substantial data on cultural functions, raw materials and manufacture techniques. The systemic knowledge, for its part, operates with properties coherence in objects and contextual relations in object environments as well. The classification represents an efficient method to detect such relations. This review scopes out the North Pontic Chalcolithic and Bronze Age and Iron Age industries. The overall comparative typological analysis includes classification and typology. The latter detects combinations of culturally significant attributes of technological and functional character; it goes beyond the scope of the paper. Instead, the artefact units have been classified on the basis of functions, technological patterns, and raw material structures. 
There is nothing from any industry that would be lacking a function within frameworks of past bone and antler processing. As AP Borodovskiy ${ }^{7}$ notes, an industry as archaeological entity is of great research importance. It catches epoch-making progress in elements of the manufacture. In the course of manufacture, the raw material resources were exploited by applying specialized skills and instruments to result in as products. This occurred in the framework of certain social and economic system with specific social patterns acting in given ethnicity and environmental settings. Considering the integrity of raw material structures, technological properties and functional attributes that characterize any distinct artefactual object of bone and antler, the manufacture output seems to include technological refuse, blanks, manufacture wastes, semi-finished products and finished products. ${ }^{7}$

Here, at the most general level of the functional classification, two sub fractions are discerned to compose an industry. The first one is equipment (aka inventory) with its acquired efficient shape and techniques applied to it. This represents all those material out-ofbody utilities serving for human adaptation needs. The equipment is recognized from blanks as well as semi-finished and finished products. But sometimes, it can be easily identified from technological refuse and manufacture wastes too. Consistent similarities in use-wear patterns and constructive modes suggest the artefacts to be attributed to the same category.

All the entities mentioned are thought to be manufacture output. Yet here I choose to highlight product's technical function(s) and manner(s) of use. Since not all artefacts are equipments, the second subfraction includes refuse and wastes without any technical function(s) which were not used at all. Further, for the sake of clarity, let us follow the scheme below (Table 1). The equipment classes, subclasses and groups have been defined through the notions of subject, process, means and product of labor (see above: resources, skills and instruments $\rightarrow$ products).

Table I The general matrix for classification of industries based on the principles of artefacts' technical functions and manners of use

\begin{tabular}{llll}
\hline Equipment & Classes & Subclasses & Groups \\
\cline { 2 - 4 } & Equipment for productive actions & Instruments & Tools \\
& & Devices \\
& & Joints \\
& Implements & \\
Equipment for non-productive actions & Instruments & Tools \\
& & Devices \\
& & Joints \\
& Implements & \\
& Accessories & Furniture \\
& & Paraphernalia \\
\hline
\end{tabular}

There are two Classes have been grouped to bifurcate technical functions of one or another artefact category towards actions of manual productive labor or adaptive manipulations of non-productive labor. There are no entities for fields of use in this part of classification (e.g., agricultural inventory, household wares, a manufacture kit etc.). A different classification should do with such sort of interrelations. Furthermore, a non-productive action with bone or antler object could be involved in to serve productive labor (e.g., a wagon ride for firewood or hay, with deer antler cheekpieces working in a horse bridle set); there were too many ways for bronze and iron knives to be used for, while the only parts of them that left are handles. So the equipped actions are discussed here instead of some equipped activity or behavior. In Classes, the artefact categories are congregated to Subclasses and Groups considering the way these may have affected other objects or interacted with them, the way resulting in rational shapes and use-wear patterning in artefacts.

Instruments form a subclass of equipment affecting natural and man-made objects in the course of purposive designing or alteration of their shapes and properties and states. The tools, devices, and joints are the groups within instrumental subclass. A tool affects objects with special working surface, the position of which is set by or is under control of a spot of grip or fixing (Figure 1) (Figure 2) ${ }^{8,9} \mathrm{~A}$ device affects objects by transmitting them amplified and directed motions from operating living beings (Figure 3 ) ${ }^{8} \mathrm{~A}$ joint affects parts of a composite tool, or a device, ensuring thereby their functioning as integral outfits (Figure 4) (Figure 5). ${ }^{10,11}$

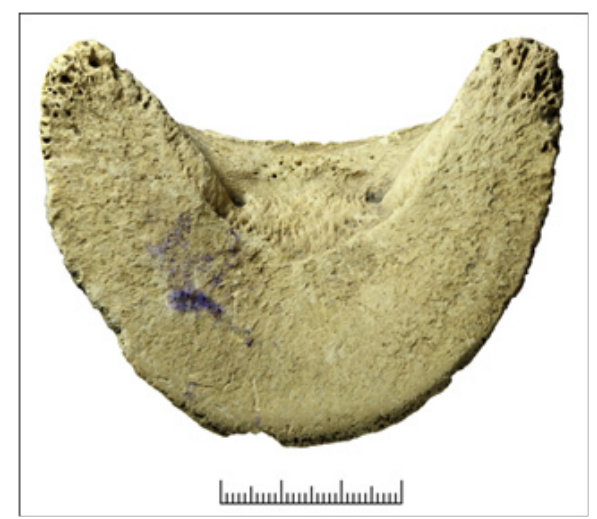

Figure I A tool of productive action representing the natural accomodat subclass. The horse $3^{\text {rd }}$ phalanx scraper from the Late Bronze Age Malopolovetskoe-3 cemetery site [8: fig. 14:2]. 


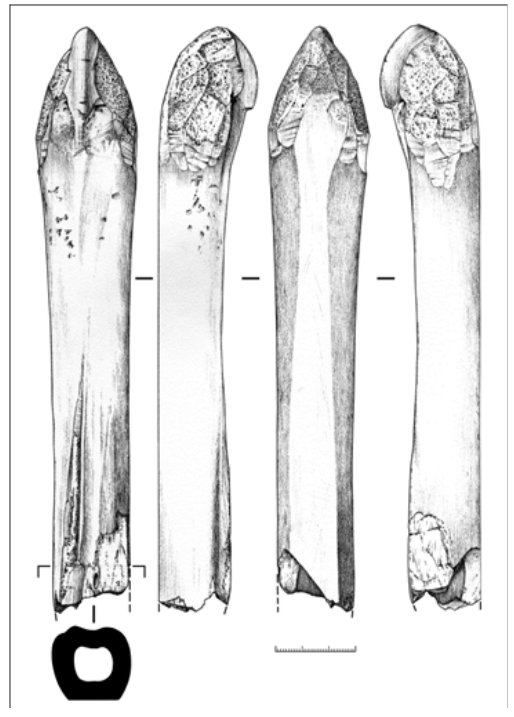

Figure $2 \mathrm{~A}$ tool of non-productive action representing the natural modificat subclass. The horse metatarsal skate from the Late Bronze Age Fascherka settlement site [9: fig. I].

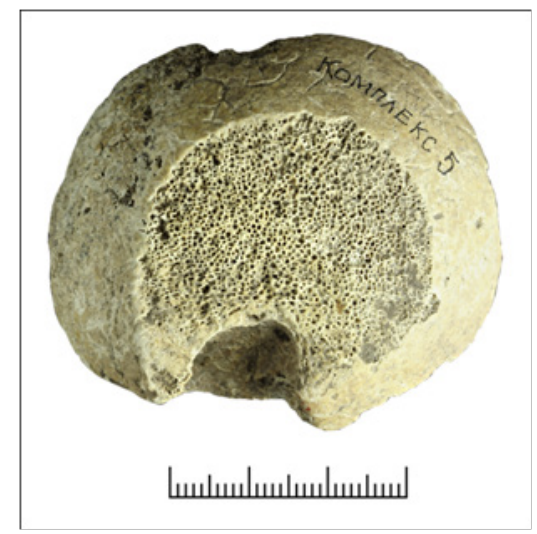

Figure $3 \mathrm{~A}$ device of productive or non-productive actions typifies the partial modificat subclass. This is the semi-finished cattle femoral head spindle whorl or a peg-top wheel from the Late Bronze Age Malopolovetskoe-3 cemetery site [8: fig. 6:6].

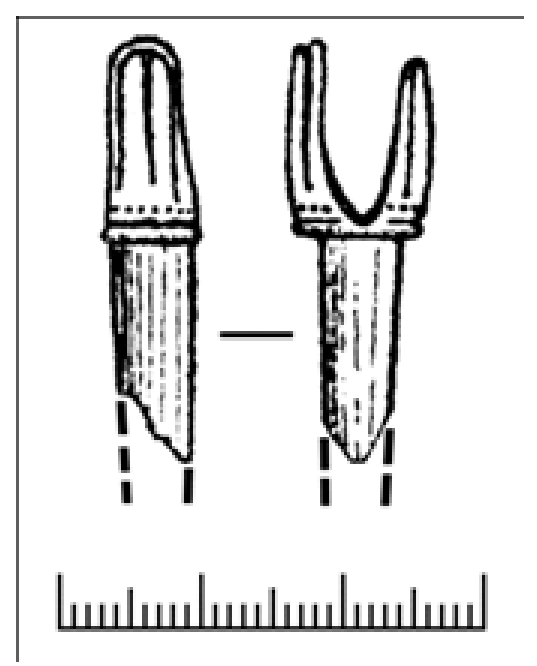

Figure $4 \mathrm{~A}$ productive joint object of the convertat technoclass. The bone arrow nock from the Late Bronze Age Bezymennoe-Il settlement site [10: fig. 2:4

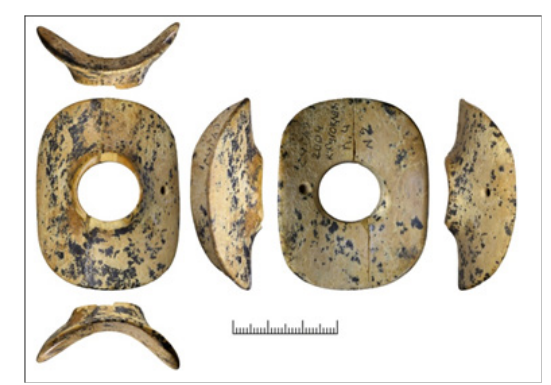

Figure $5 \mathrm{~A}$ non-productive joint object of the convertat technoclass. The bone belt buckle from the late Middle Bronze Age Sugokleia barrow mound, grave 4 [II:Abb. 6].

Implements are a subclass of equipment performing ancillary role of mediator in purposive designing or alteration of shapes and properties and states in natural and man-made objects (Figure 6-8). ${ }^{12}$ Accessories compose a subclass of equipment, the very states of which while being set up or changed constitute an essence of activities. The furniture and paraphernalia are the groups within accessorial subclass. The furniture represents immovable and inactive details of furnishing tools and devices (Figure 9) (Figure 10). ${ }^{13,1}$ The paraphernalia represent movable and active outfits of figurative and symbolic character (Figure 11)..$^{14}$

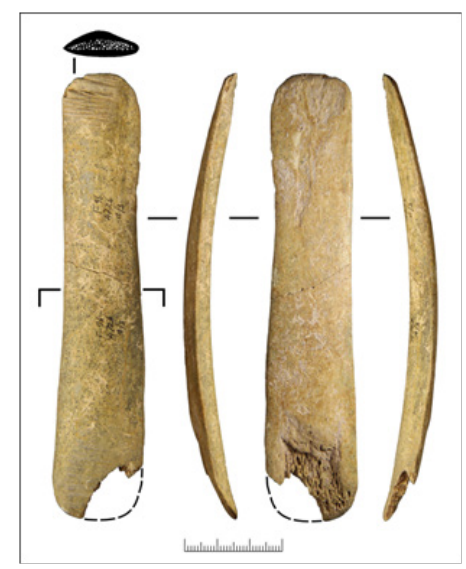

Figure 6 An implement of productive action as an example of partial modificat. The cattle rib staple cutting lamella found at the Late Bronze Age Gorniy-I settlement site [I2: fig. 7].

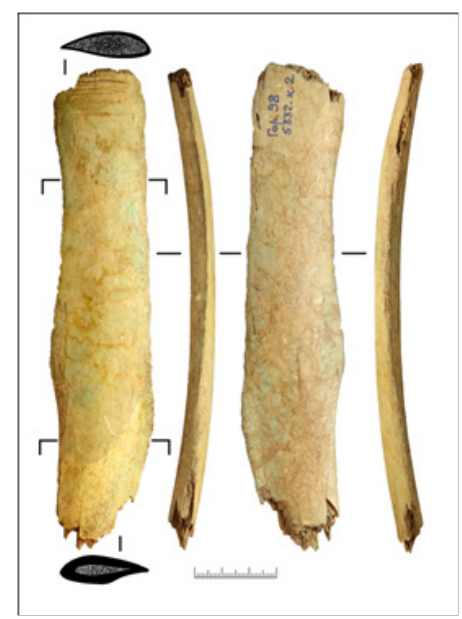

Figure 7 An implement of productive action as an example of partial accomodat. The cattle rib staple cutting lamella found at the Late Bronze Age Gorniy-I settlement site [12: fig. 8]. 


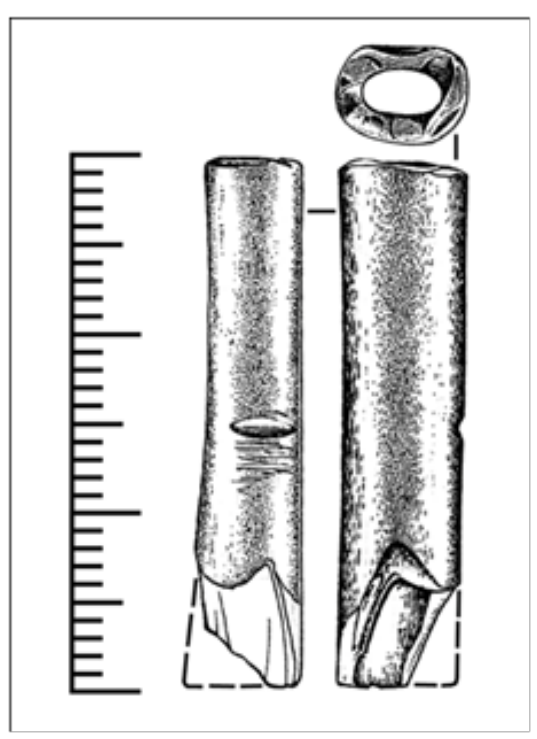

Figure $8 \mathrm{An}$ implement of non-productive action of the partial modificat subclass. The sheep tibia tubular sheath from the Late Bronze Age Kirovo settlement site.

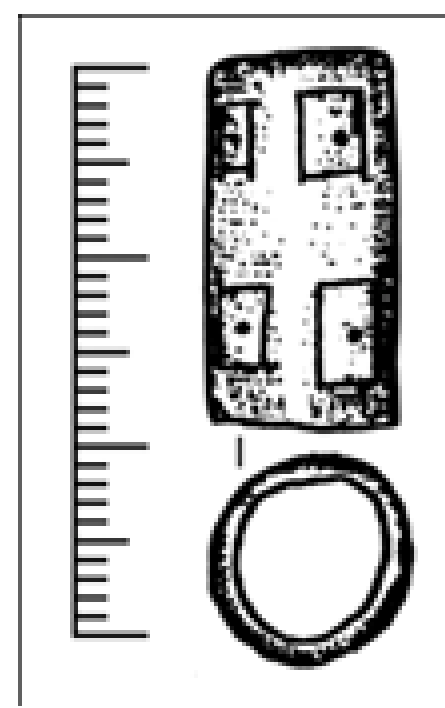

Figure 9 A furniture productive object of the partial modificat subclass. The long bone handle clamp sleeve [13: fig. 63:24].

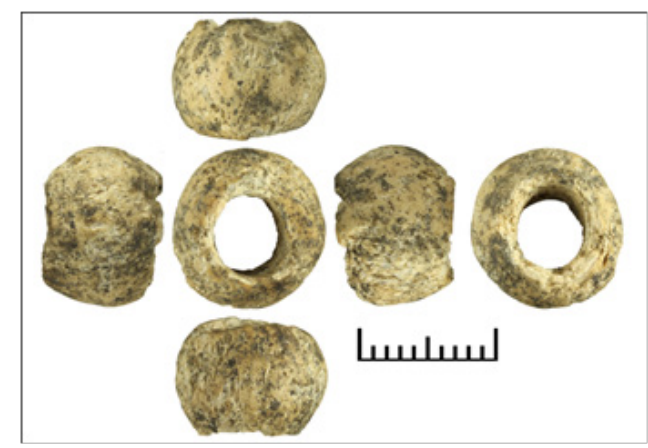

Figure $10 \mathrm{~A}$ furniture non-productive object of the convertat technoclass. The red deer antler bead from the Late Scythian Glinoe cemetery, grave 4 in the barrow mound 46 [I: fig. 16].

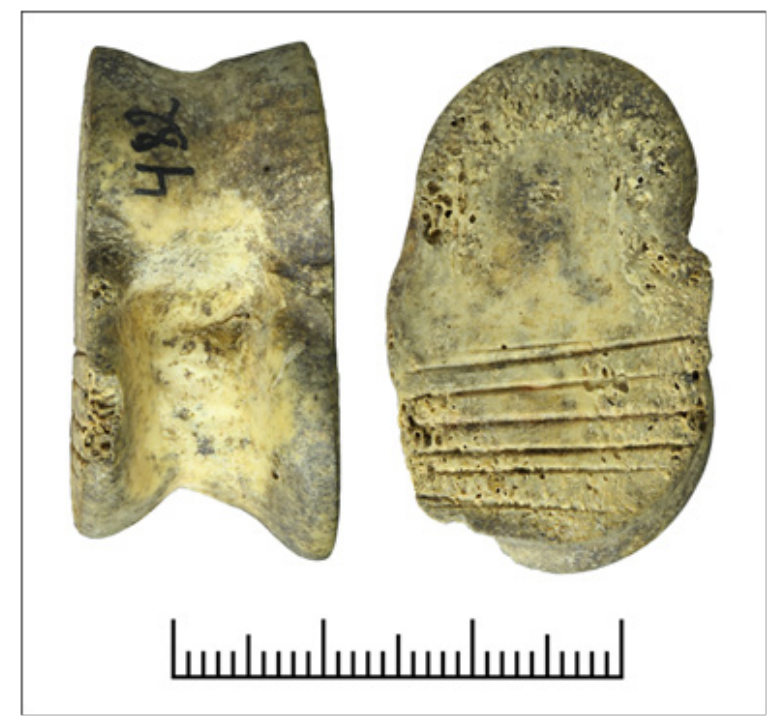

Figure II A paraphernalia object of the natural modificat subclass. The sheep knucklebone from the Late Chalcolithic Mihailovka settlement site, pit dwelling 3 [14: fig. 3: 5].

It should be emphasized, that what is classified in the case are the functions of the artefacts of industry, and are not functions of past equipments which entirely or only partially consisted of osseous materials. It also should be stressed, that general technical functions in some artefacts of industry would not have been occurring somewhere else beyond past composite equipments. From this point of view, a cattle femoral head spindle whorl was useless without wooden spindle rod itself; two deer antler cheekpieces once worked together in a bridle set, and a handle of bone complemented an awl or a knife with sufficient grip area. So the knife handle is likely to be ascribed to the joints as parts of the past composite tools and not to the composite tools themselves. The interrelations of this kind seem to go out of this classification's bounds to be grouped then in a special way. The technical functions oriented classification does not concern any typological attributes (e.g., one-piece knife handle vs composite knife handle) but categories of all handles, all raw hide breakers and more.

The great advantage of the approach is that it aims to embed objects of ambiguous purposes and functions into the system. For instance, it is sufficient that a working surface is only detected to approve an object to be a tool. It would take some time to wait, however, before this tool object is attributed to one class or another by revealing a highly probable mode of provenance for the use-wear traces over the working surface. Certainly, any definitive suggestions are to make on the diversiform basis of traceological and osteological data. According to AP Borodovskiy, ${ }^{7}$ technological systems in which "raw material has been gradually altered by losing ... its natural shape" are applicable to the whole aggregation of skeletal bones, antler, horn cores and sheath, teeth, tusks, etc. Progressive modification process together with increase of manufacturing complexity is detectible on the technological research level from basic blanks data in the form of technological systems. These are:
A. The use of the natural shape in full,
B. The use of the natural shape in part,
C. The use of the fractured raw material, and 
D. Cutting raw materials out and splitting them down.

The turning basic blanks into products and the next modifying them from utilization are being studied on the functional research level.

Being further development of the construct discussed, the present systematization considers the increasing manufacturing complexity along with natural shapes patterns that contributed to the general forms of things. The raw material structure analysis has regard to the raw material elements with all applied structural modifications. The technological analysis detects manufacture products, operational sequences, while the functional analysis reveals interconnections between shape of an item and its purpose. As a result of such extensive research, the listed below object techno classes (and subclasses) have been distinguished.

The accommodates are the unmanufactured osseous objects used as complete natural units (natural $a$.) or in part (partial $a$.). The partial accomodats are best to be described as bone expediency tools. ${ }^{15}$

In modificats, the raw material specimen is altered with natural outline preserved (natural $\mathrm{m}$.) or with part of its elements remained intact (partial $m$.).

The convertats represent residually survived raw material elements

and outlines. 3,4
Table 2 The updated matrix for classification of the North Pontic Late Bronze Age industries

Figures 1-11 display representative objects from each of the three technoclasses mentioned above.

\section{A special sample case from the north pontic late bronze age}

Let us now consider a vivid example of grouping industries from a distinct archaeological time range at the regional level (Table 2). In the successive sequence of the Sabatinovka culture and the Belozerka culture, the first one is dated back to the $16^{\text {th }}-13^{\text {th }}$ centuries $\mathrm{BC}$, i.e. the Bronze B-D periods by the European scale. The younger culture dates back to the $12^{\text {th }}-10^{\text {th }}$ centuries $\mathrm{BC}$ which correspond to the Hallstatt A-B1 periods of the same scale. In the aspect of metal production activity, the Sabatinovka and the Belozerka phenomena fall in its III/ IV-VII periods in the south of Eastern Europe. ${ }^{17}$ I leave aside for the time being all possible varieties of interconnections that could be observed through such a superposition of matrices. It is quite obvious, however, that the stability in shapes and the strength of raw materials determined the fact that tools play a decisive role in accomodats and simple (natural) modificats. The natural outlines of raw materials gradually disappear in a variety of partial modificats and convertats, which are mainly represented by a class of non-productive equipment. Thus, here one can observe peculiarities of a typological nature for the forthcoming analyses, estimations, and discussions.

Now let's take a look at how the classifications relate (Table 3).

\section{Classes/subclasses \& groups}

\section{Equipment for productive actions (processing or modifying smth)}

Equipment for nonproductive actions (adapting or organizing Smth)
Adzes, Arrow Heads, Awls, Card Comb Spikes, Chisels, Fish Hooks, Fish Scalers, Hair Comb Spikes, Hammer Heads, Harpoon Points, Jack-Planes, JackPlane Breakers, Needles, Potters' Styli, Raw Hide Breakers, Scrapers, Sheepskins Breakers, Spatulae, Thong-Smoothers, Trowels

Tools with toolrelated working parts

Instruments

Arrow Nocks, Awl Handles, Fish Hook Rods

Devices with devicerelated units
Nozzles, Spindle Whorls, Weaving Boards

Awl Thimbles, Gauge Markers, Staple Cutting Lamellae

Handle Clamp Sleeves

\section{Pins, Plectra, Skates}

Belt Hooks, Buttons,

Cheekpieces, Clasps, Fasteners, Harness Buckles, Harness Spreaders, Noseband Plaques

Bullroarers, Drinking Straws, Quail-Pipes, Peg-Top Wheels

Tubular Sheaths, Vessels

Appliqués, Beads, Belt End Tips, Pendants

Dolls-Idols, Knucklebones

Paraphernalia

Table 3 The North Pontic Late Bronze Age artefacts' technical functions and manners of use distributed among technoclasses. The equipments for productive actions are represented in regular font, while the equipments for non-productive actions are given in bold italics

\begin{tabular}{lllll}
\hline \multirow{2}{*}{ Tc } & Instruments & Implements & Accessories & Furniture \\
\cline { 2 - 4 } & Tools & Joints & Devices & Paraphernalia \\
\hline $\mathrm{Na}$ & Jack-Planes & & Pendants \\
& Jack-Plane Breakers & & \\
\hline
\end{tabular}


Table Continued....

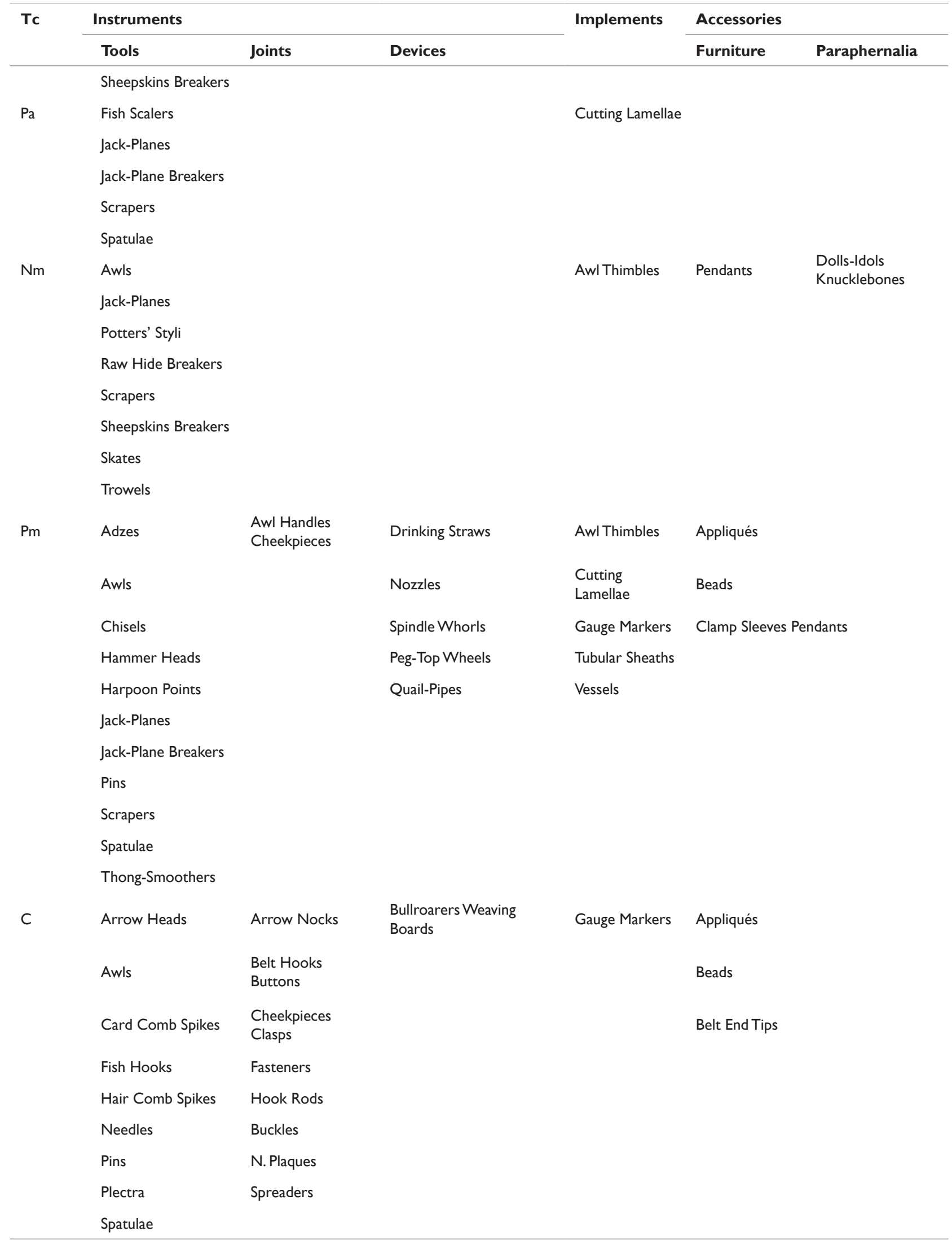

TC, technoclasses; NA, natural accomodats; PA, partial accomodats; NM, natural modificats; PM, partial modificats; C, convertats 


\section{Conclusion}

The ordering of the material, which has been provisionally presented in the form of technoclasses triplicity, proceeds from the very foundations of the classificatory procedure and is complex, with structural raw material and functional data included. With this grouping of the material, the grouping by artefacts' technical functions is quite compatible to clarify the typological relationships. In the group of tools, it is possible to refer to the tools themselves and tool-related pieces as well, in order to find out how many composite, stationary and other complex tools there were existed in the past. The same seems applicable to the devices group. In the same way, it is supposed to find out what other materials and substances were involved in order to bring composite equipment into an active state. And, of course, there is a room for inclusion in the system of so far uncertain archaeological osseous objects.

\section{Acknowledgements}

None.

\section{Conflict of interest} article.

Author declares there is no conflict of interest in publishing the

\section{References}

1. Pankovskiy VB. Examining Raw Materials and Surface Modifications in Bone and Antler Objects from Glinoe Cemetery. In: Telnov NP, et al., editors. The Scythian Cemetery of the $3^{\text {rd }}-2^{\text {nd }}$ Centuries BC Near Glinoe Village (Archaeological Sites of the Dniester Region III), STRATUM Publishing House, Moldova. 2016. p. 1003-1038.

2. Klein LS. Archaeological Typology. The Academy of Sciences of the USSR, Russia; 1991. p. 447.

3. Pankovskiy VB. The Cheekpieces of Slobozia. Stratum plus. 2015;3:265-296.

4. Pankovskiy VB, Girya EY, Sablin MV. Discrimination between Prehistoric Artworks and Naturally Modified Faunal Remains in the Light of Traceological Studies. Stratum plus. 2015;1:169-184.

5. ChoykeAM. The bone tool manufacturing continuum. Anthropozoologica. 1997;25-26:65-72.
6. Pankovskiy VB. Bone Buckle Chaîne Opératoire in the Babine Culture. Donetsk Archaeological Collect. 2016;18-19:44-77.

7. Borodovskiy AP. The Ancient Bone Carving in the south of Western Siberia (from the second half of the $2^{\text {nd }}$ millennium $\mathrm{BC}$ to the first half of the $2^{\text {nd }}$ millennium CE). The Institute of Archaeology and Ethnography. Russia; 1997. p. 224.

8. Pankovskiy VB. The problem of the bone industry in the Trzciniec cultural circle (Malopolovetske-3). The problems of the archaeology of the Middle Dnieper region. To the $15^{\text {th }}$ anniversary of the foundation of Fastiv State Museum of the Regional Studies. Ukrainian; 2005. p. $120-142$.

9. Koloda VV, Pankowski VB, Razumov SN, et al. The Chalcolithic and Bronze Age Bone and Lithic Objects from Faschevka Settlement Site. Arheolohia. 2017;2:76-89.

10. Usachuk AN. The Bone Objects Collection from the Timbered Graves Culture Settlement Bezymennoe II. The Northeast Azov area in the system of the Eurasian antiquities (the Chalcolithic-the Bronze Age). Proceedings of the International conference, Part II. Donetsk State University Publ, Ukraine; 1996. p. 21-27.

11. Pankowski V. The Buckles of Sugokleya. In: Nikolova AV, Kaiser E, editors. Der Grabhügel 'Sugokleja' in der zentralen Ukraine. Archäologische, anthropologische und isotopenchemische Studien, Ukraine; 2017.

12. Pankowski VB, Antipina EE. A New Category in the Late Bronze Age Bone Industries. 2017.

13. Kolotukhin VA. The Late Bronze Age in Crimea. Stratum Plus. 2013;2:139.

14. Pankovskiy VB. The industry of the skeletal materials from the lower layer of Mihailovka. In: Kotova NS, editors .The Dereivka culture and the sites of the Lower Layer of Mihailovka type. Maidan Publications, Ukraine; 2013. p. 449-483.

15. Lyman RL. Broken Bones, Bone Expediency Tools and Bone Pseudotools: Lessons from the Blast Zone around Mount St. Helens, Washington. American Antiquity. 1984;49(2):315-333.

16. Pankovskiy VB. Bone, antler and horn industries of the Late Bronze Age in the North Pontic Area. PhD thesis in historical science, Ukrainian; 2012. p. 15.

17. Bochkarev VS. Stages in the Development of Metal Production in the Late Bronze Age in the south of Eastern Europe. Stratum plus. 2017;2:159-204. 